\title{
Repensar a linguagem: Wittgenstein e Davidson contra o representacionismo
}

\author{
Aldo Litaiff* \\ Cristiano Neves**
}

\begin{abstract}
Resumo:
O presente artigo tem por objetivo expor a relevância para a área da linguagem da crítica que Wittgenstein faz à teoria da representação. Em Investigações Filosóficas, o autor formula a tese dos Jogos de Linguagem, que pode ser entendida como uma solução terapêutica para problemas não apenas filosóficos, mas de várias áreas do conhecimento humano. Em um segundo momento busca aprimorar a tese de Wittgenstein valendo-se dos estudos de Donald Davidson sobre a importância do aspecto social da linguagem. Compreender a forma da linguagem utilizada em contextos diferentes como Jogos, significa compreender um campo onde indivíduos possam interagir uns com os outros através de diálogos que respeitam as mesmas regras para o uso das palavras.
\end{abstract}

\section{Palavras-chave:}

Jogos de linguagem; regras; representação; uso

\section{Introdução}

Na obra Investigações Filosóficas, o filósofo austríaco Ludwig Wittgenstein (18891951) oferece um novo ponto de vista referente ao estudo da linguagem: o significado das palavras não depende daquilo a que elas se referem, mas de como elas são usadas. Tal pensamento formula uma crítica às teorias do significado que são justificadas pela filosofia clássica da representação. A visão da linguagem como representação atribui ao pensamento a função de ligar a linguagem ao mundo. $A$ lógica da representação não apenas pressupõe que a intenção de uso da linguagem é sempre representar, como também concebe a representação como uma espécie de espelhamento do mundo na linguagem pelo pensamento. Tais teorias exploram a idéia de que para cada palavra da linguagem há uma referência, uma coisa ou objeto que the corresponde, sendo essa correspondência aprendida e ensinada pelo procedimento de nomeação. É na perspectiva de uma crítica radical à concepção da linguagem como representação do mundo que a descrição do fundamento da linguagem nas Investigações vai vincular-se a uma estrutura "antropológica", a uma "forma de vida". Essa é a razão pela qual, para Wittgenstein, as regras da gramática não poderiam ser apenas regras de representação. Ele chama a atenção para a distinção entre o uso da linguagem como representação e seu uso como instrumento que leva à ação (FAUSTINO, 1995, p. 31).

\footnotetext{
* Dr. em Antropologia Cultural pela Universidade de Montréal (Canadá). Professor da Pós-graduação
} em Ciências da Linguagem da Unisul.

** Doutorando do PPG em Ciências da Linguagem da Unisul. 
Wittgenstein propõe que as regras de nossa gramática não são algo privado, mas de domínio público, temos desde a origem a presença da dimensão social. O falar da linguagem é parte de uma atividade ou forma de vida. Qualquer tentativa de compreender a comunicação verbal deve considerá-la em seu contexto natural como parte de um empreendimento mais amplo. A princípio, isto pode não parecer difícil, não havendo nada mais à linguagem do que as transações públicas entre falantes e intérpretes, e as aptidões para tais transações. Contudo, esta tarefa ilude, pois o fenômeno lingüístico é um fenômeno, biológico ou físico, descrito num vocabulário exótico de significado, referência, verdade, asserção e assim por diante.

Para Wittgenstein, o "limite de linguagem" mais importante, não consistia na fronteira externa da linguagem, mas na sua limitação interna, ou seja, as inevitáveis restrições do que se pode dizer numa linguagem, sobre essa linguagem. 0 limite da linguagem é fixado pela totalidade de objetos nomeados na linguagem. Aprender a linguagem significa compreender o papel que exercem nas nossas vidas as diferentes espécies de enunciados em diferentes circunstâncias. Podese imaginar que todos os processos do uso das palavras são jogos, por meio dos quais as crianças aprendem sua língua materna (WITTGENSTEIN, 1975, p. 16).

\section{A concepção agostiniana da linguagem}

No primeiro parágrafo das Investigações, Wittgenstein resgata a imagem agostiniana da linguagem trazendo à tona o fio condutor de sua crítica. Ao nomearmos algum objeto e em seguida nos voltarmos para ele percebemos que o objeto em questão foi designado por um som. A aprendizagem na concepção agostiniana se limitaria à compreensão de que uma coisa é designada por uma palavra e ao aprendermos essa palavra conseqüentemente desenvolvemos a capacidade de emprego em frases diferentes. Sendo as palavras nomes de objetos e as frases combinações de palavras, a principal explicação da palavra seria portanto a ostensão e o sentido de uma palavra seria o objeto que ela nomeia. Nomear e descrever seriam as duas funções da linguagem. A imagem agostiniana seria particularmente nociva porque várias teorias sofisticadas enraizavam-se nela, que traduz assim uma doença do entendimento "seduzido" por essa imagem (CHAUVIRÉ, 1991, p. 142).

A descrição agostiniana do aprendizado, fazendo-se valer da noção de "significado" como aquilo que se obtém mediante a referência a alguma coisa ou objeto, negligencia, segundo Wittgenstein, a distinção de espécies de palavras e padece de uma generalização indevida: o ensino de todas as palavras é descrito segundo o modelo de ostensão de um objeto. Sob tal ótica ensinar consistiria, em todos os casos, em mostrar quais coisas são designadas pelas palavras; e aprender consistiria, em todos os casos, em ver ou compreender quais coisas estão sendo por elas designadas. Assim, a relação que funda o fenômeno da compreensão na linguagem seria uma relação de quem fala e de quem ouve não diretamente com as palavras, mas com as coisas que elas significam. Conhecer uma palavra seria, desse ponto de vista, conhecer a coisa ou o objeto que ela nomeia; isso quer dizer 
simplesmente que, à luz da imagem agostiniana da linguagem, todas as palavras se comportam gramaticalmente como nomes e que a "definição ostensiva" estabelece uma regra gramatical fixa para definir o significado de todas as palavras da linguagem (FAUSTINO, 1995, p. 15).

Wittgenstein argumenta que Santo Agostinho não fala de uma diferença entre espécies de palavras. Quem descreve o aprendizado da linguagem desse modo, pensa primeiramente em substantivos tais como "mesa", "cadeira", "pão", em nomes de pessoas, e apenas em segundo lugar em nomes de certas atividades e qualidades, e nas espécies de palavras como algo que se terminará por encontrar. O pensamento agostiniano cabe bem numa representação primitiva da maneira pela qual a linguagem funciona, ou que um sistema de comunicação não pode ser considerado como tudo aquilo que chamamos de linguagem. E isso deve ser dito em muitos casos em que se levanta a questão: "Essa apresentação é útil ou não?". A resposta é, então: "Sim, é útil"; mas apenas para esse domínio estritamente delimitado, não para o todo que se pretendia apresentar (WITTGENSTEIN, 1999, p. 28).

A interação entre adultos e crianças na situação de ensino ostensivo fornece as condições necessárias para o surgimento da linguagem e do pensamento proposicional, criando um espaço no qual pode haver êxito e fracasso. O que está claro é que somente podemos dizer que as crianças pensam que algo é vermelho, ou é uma bola, se ela aprecia a distinção por si mesma: a criança pensa que algo é vermelho ou uma bola somente se ela está, em algum sentido, consciente de que é possível um erro. O "ensino ostensivo", tal como entende Wittgenstein, prepara a criança para o uso de uma palavra a partir de sua inserção em diferentes jogos de linguagem, isto é, em diferentes circunstâncias de seu uso e, portanto, pela delimitação das diferentes finalidades que a palavra pode cumprir, de modo bastante diferente da "definição ostensiva", que consiste em uma resposta definitiva à pergunta pela denominação. O "ensino ostensivo" não visa estabelecer uma relação da palavra com algo fixo ou com uma entidade correspondente. Pelo contrário, requer que o aprendizado se dê segundo normas e atividades de caráter muito mais abrangente que o ato exclusivo de captar e guardar relações fixas entre nomes e denominados. A analogia das palavras com peças de um jogo de xadrez ou com ferramentas procura justamente negar que a "forma" do signo, quando destacada ou abstraída dos contextos possíveis de seu uso, seja a instância máxima de determinabilidade de suas funções gramaticais (FAUSTINO, 1995, p. 16).

É difícil exagerar a magnitude do passo de um aprendiz na disposição para responder a estímulos de um certo tipo, para empregar um conceito com a consciência da chance de erro. É o passo da reação ao estímulo mais próximo ao pensamento de dispor objetos e eventos, o passo da mera resposta condicionada, para o que Wittgenstein chamou de "seguir uma regra". É onde entra o conceito de verdade, pois não há nenhum sentido em dizer que uma disposição é um erro, pois não se pode falar em "seguir" uma disposição, mas pode-se falhar em seguir uma regra. As crenças que temos em mente são nossas crenças perceptuais, as crenças que são causadas diretamente pelo que vemos, ouvimos e percebemos também pelos 
outros sentidos. Estas podem ser, em geral, verdadeiras, pois seu conteúdo é, na realidade, determinado pelo que tipicamente as causam. Nossos conceitos são nossos, mas isso não significa que eles não possam verdadeiramente e utilmente descrever uma realidade objetiva (DAVIDSON, 2002, p. 148).

\section{Os jogos de linguagem}

O ensino de uma palavra, na visão de Wittgenstein, seria comparável ao ensino do uso de uma peça num jogo de xadrez: assim como não aprendemos as funções da peça denominada "o rei do xadrez" simplesmente ao nos ser mostrada a formada figura de um rei, mas ao nos serem mostrados ou descritos lances válidos com esta figura no interior do jogo, assim também não aprendemos o desempenho gramatical de uma palavra (o que podemos "fazer" com ela) num determinado jogo de linguagem pela simples identificação do nome com algum referência, mas pelo exemplo de seu emprego em circunstâncias variadas. Assim, torna-se possível descrever de maneira muito mais adequada o aprendizado do uso das palavras em relação às quais não se pode apontar um referente, tais como os chamados "substantivos abstratos", por exemplo (FAUSTINO, 1995, p. 23).

Na práxis do uso da linguagem, um parceiro enuncia as palavras, o outro age de acordo com elas; na lição de linguagem, porém, encontrar-se-á este processo: o que aprende denomina os objetos. Isto é, fala da palavra, quando o professor aponta para o objeto. Podemos também imaginar que todo o processo do uso das palavras é um jogo por meio do qual é possível se ensinar uma língua. Wittgenstein chama esse processo de denominação dos objetos e da repetição das palavras pronunciadas em "Jogos de Linguagem", o conjunto da linguagem e das atividades com as quais está interligada. "Eu sei" significa freqüentemente: "tenho razões fundamentadas para a minha afirmação". Assim, se o outro conhecer o Jogo de Linguagem, tem de ser capaz de imaginar como é que alguém pode saber esse tipo de coisa. Os Jogos de Linguagem figuram muito mais como objetos de comparação, que, através de semelhanças e dessemelhanças, devem lançar luz sobre as relações de nossa linguagem (WITTGENSTEIN, 1969, p. 29). A reflexão sobre a aquisição e o aprendizado da linguagem, isto é, o exame das formas primitivas de seu uso cumprem a função terapêutica de purgar ou purificar a gramática filosófica, procurando suprir a concepção das "significações" como ligações entre o "corpo" e a "alma" da linguagem ou entre "espírito" e a "letra". A noção de "terapia" em Wittgenstein tem a finalidade de purgar completamente um mal, procede de modo a trazer à tona, da maneira mais vigorosa possível, os seus sintomas. Esse "mal" diria respeito não à linguagem ordinária, que deve ser descrita, mas a uma determinada maneira de conhecer a sua gramática: à concepção de que o simbolismo ordinário traz embutido na sua forma aparente uma intencionalidade oculta que lhe é própria e inerente, e à suposição dogmática de que a descrição gramatical tem como tarefa desentranhar, desvelar a partir do corpo material dos signos, perceptível aos sentidos, a intencionalidade imperceptível com a qual são usados (FAUSTINO, 1995, p. 23).

Em Investigações Filosóficas, Wittgenstein deixa claro que a tarefa dos jogos real- 
mente jogados não pode ser cumprida por regras, seja qual for o sentido em que suas expressões lingüísticas ou simbólicas forem tomadas. Por exemplo, tendo em vista parcialmente o papel que atribuíra à expressão simbólica de uma regra em sua obediência. A expressão simbólica era na verdade uma descrição mitológica do uso de uma regra. Portanto, é o jogo de linguagem integral que constitui a relação nome-objeto, e não uma regra especifica ou critério (HINTIKKA, 1994, p. 252).

Sobre isso Wittgenstein complementa:

A regra pode ser um auxílio no ensino do jogo. É comunicada àquele que aprende e sua aplicação é exercida. Ou é uma ferramenta do próprio jogo. Ou: uma regra não encontra emprego nem no ensino nem no próprio, nem está indicada num catálogo das regras. Aprende-se o jogo observando como os outros o jogam. Mas dizemos que se joga segundo esta ou aquela regra, porque um observador pode ler essas regras na práxis do jogo, como uma lei natural que as jogadas seguem. Mas como observador distingue, nesse caso, entre um erro de quem joga e uma jogada certa? Há para isso indícios no comportamento dos jogadores. Pense no comportamento característico daquele que corrige um lapso. Seria possível reconhecer que alguém faça isso, mesmo que não compreendamos sua linguagem. (WITTGENSTEIN, 1999, p. 48)

Muitos problemas do cotidiano nascem de uma má interpretação de nossas formas lingüísticas, mal-entendidos são provocados, entre outras coisas, por certas analogias entre as formas de expressão em diferentes domínios de nossa linguagem. O nome deve designar propriamente o simples e o denominar consistiria como que num processo oculto, uma ligação estranha de uma palavra com um objeto. De acordo com isto, ao tentar explicar o que é um nome, ao invés de considerar os diferentes empregos da palavra nome, fixa-se num objeto diante de si, e repete-se inúmeras vezes um nome. Em filosofia, não basta aprender o que tem de se dizer em todos os casos sobre um objeto, mas também como devemos falar sobre ele. Temos sempre de começar por aprender o método de o abordar. Ou uma vez mais: em todo problema sério, a incerteza estende-se até as raízes do problema. Os resultados da filosofia consistem na descoberta de um simples absurdo qualquer e nas confusões que o entendimento recebeu ao correr de encontro às fronteiras da linguagem. Elas, as confusões, nos permitem reconhecer o valor dessas descobertas.

Sobre a natureza dos problemas da filosofia, Wittgenstein argumenta:

Gostaria de fazer agora uma observação geral sobre a natureza dos problemas filosóficos. A falta de clareza na filosofia é atormentadora. É sentida como vergonhosa. Sentimos: não nos conhecemos da maneira como nos deveríamos conhecer. E, no entanto, não é assim. Podemos muito bem viver sem estas distinções, e também sem nos conhecermos. (WITTGENSTEIN, 1975, p. 57)

A tese de Wittgenstein pode ser entendida como uma metodologia terapêutica 
de modo a evitarmos mal-entendidos lingüísticos, isto é, interpretações errôneas do emprego ou da gramática de nossa linguagem. À medida que a gramática designa as regras do emprego de uma palavra, ou também o complexo das regras que constituem uma linguagem, ela é anterior ao uso concreto das palavras e da linguagem nas situações particulares da vida. A tese de Wittgenstein se diferencia da ciência, não provém de novas invenções ou descobertas, mas da compreensão de algo que sempre já se encontra diante de nossos olhos, nas regras do emprego de nossas palavras, porque aí se encontra também a origem de nossos problemas (SPANOL, 1989, p. 141). Wittgenstein, nas Investigações Filosóficas, tem bases em apenas um tipo de regra, qual seja, a função matemática. Isto porque este tipo de regra, parece nos fornecer as condições necessárias e suficientes para a aplicação de palavras e, também, porque as regras da matemática nos servem como paradigmas de "certeza" Contudo, sabemos que as regras possuem diversas formas: definições ostensivas, diagramas, explicações por enumeração, definições verbais, tabelas de verdade, paráfrases contextuais, regras de jogos, regras que impõem algum tipo de obrigação, regras que conferem direito, etc. Certamente uma tal construção pode, por sua vez, ensinar-nos algo acerca do uso efetivo das palavras (WITTGENSTEIN, 1977, p. 13).

O holismo está no centro da posição pragmática na medida em que ser pragmatista é ser contextualizador ou antiessencialista. O pragmatista é aquele que quer "destruir a distinção entre intrínseco e extrínseco - entre essência interna de $\mathrm{x}$ e uma área periférica de $\mathrm{x}$ que é constituída pelo fato de que $\mathrm{x}$ está em certas relações com outros itens que constituem o universo". Para os pragmatistas, não existe uma coisa como a característica não-relacional de um $x$, tal como não existe uma coisa como a natureza intrínseca, a essência de $x$. Assim, não pode existir algo como uma descrição que iguale o modo como $x$ realmente é, fora da sua relação com as necessidades ou consciência ou linguagem humana. Os pragmatistas, assim, agem com o objetivo de abandonar a disposição de tomar o "conhecer as coisas" como completamente diferente e oposto de "usar as coisas". A pretensão de conhecer $x$ é a "pretensão de estar apto a fazer algo com x ou algo a x, pôr x em relação com outra coisa" (GHIRALDELLI JR., 1999, p. 32). Seguir uma regra, fazer uma comunicação, dar uma ordem, jogar uma partida de xadrez são hábitos (costumes, instituições). Compreender uma frase significa compreender uma linguagem. Compreender uma linguagem significa dominar uma técnica (WITTGENSTEIN, 1975, p. 91).

Esse holismo pode ser entendido como as explicações de significado funcionam enquanto regras em nossas práticas cotidianas com as palavras. Além disso, quando um falante sabe o que uma palavra significa ou quando a compreende, possui habilidade para explicá-la, justificar os seus usos, corrigir enganos nas aplicações desta palavra. De modo que, tal pessoa manifesta a capacidade característica do seguir regras ao usar a palavra. Dessa forma, os usos que uma pessoa faz de uma expressão, para a qual possui explicação, constituem um ato de seguir uma regra (qual seja, a explicação dada para a palavra). 


\section{A tese de Davidson}

Donald Davidson (1917-2003) propõe um método que torna possível o desacordo provido de sentido, e isto depende inteiramente do fato de haver algum fundamento no acordo, que pode se apresentar de duas maneiras: ora ele vem do fato que os locutores têm em comum frases "tidas-por-verdadeiras", ora ele pode ser mediatizado globalmente por uma teoria da verdade elaborada pelos intérpretes e locutores. Tal método é chamado de "triangulação", quando em um diálogo ambas as partes estiverem dispostas a não defenderem acirradamente seus pontos de vista e ouvir o que a outra parte tem a dizer sem interesses metafísicos, é possível se chegar a acordos deixando para trás preconceitos disciplinares que há séculos retardam as possibilidades de criação de um diálogo coerente. Uma noção do conceito de verdade, da distinção entre pensar que algo é assim e algo ser assim, depende da norma que pode ser fornecida somente pela comunicação intepessoal (DAVIDSON, 1994b, p. 8).

Em um diálogo, uma das partes, acha interessante um certo comportamento da outra, e cada uma acha que o comportamento observável da outra é correlato a eventos e objetos que ela acha interessantes no mundo. Esta é a base do pensamento e da aprendizagem da linguagem. Pois, enquanto o triângulo, ligando duas pessoas e cada uma delas aos objetos comuns do mundo, não está completo, não pode haver resposta para a questão e saber se uma pessoa, discriminando estímulos entre elas, discrimina estímulos surgindo na superfície sensorial ou em qualquer lugar de seu exterior ou em seu interior. É preciso ser dois para triangular.

Davidson salienta:

A comunicação lingüística, o instrumento indispensável da compreensão interpessoal refinada, repousa sobre enunciados mutuamente compreendidos, cujos conteúdos são como finalmente fixados pelos padrões e causas das sentenças sustentadas verdadeiras. $O$ calço conceitual da interpretação é uma teoria da verdade; a verdade, então repousa, no fim, sobre a crença e, ainda mais fundamentalmente, sobre as atitudes afetivas. (DAVIDSON, 2002, p. 107)

Davidson argumenta que não podemos fixar significação clara à noção de ordem de um objeto único (o mundo, a natureza, etc.) enquanto não compreendermos que estes objetos consistem em outros objetos. Alguém que decide colocar ordem num armário arruma as coisas que contém este armário. Se lhe dizem para não colocar em ordem os sapatos e as camisas, mas o próprio armário, você ficará perplexo. Como você colocaria ordem no Oceano Pacífico? Estendendo suas margens, talvez ou mudando a localização de suas ilhas ou matando seus peixes. Uma linguagem pode conter predicados simples cujas extensões não correspondem a predicados simples, nem mesmo a nenhum predicado, numa outra linguagem. O que nos permite em tais casos tecer estas observações é uma ontologia comum às duas linguagens, que carregam conceitos que individualizam os mesmos objetos.

Segundo Davidson a interdependência da crença e da significação acha sua fonte 
na interdependência de dois aspectos da interpretação do comportamento lingüístico:

Admitamos que o discurso de um indivíduo só possa ser interpretado por alguém que tem um conhecimento muito vasto do que o locutor acredita (e do que ele deseja e do que ele tem intenção de fazer), e que as distinções finas entre as crenças sejam impossíveis na falta de um discurso que se compreenderia; como, nessas condições, vamos interpretar o discurso ou atribuir inteligivelmente crenças e outras atitudes? Está claro que devemos ter uma teoria que dê conta das atitudes, ao mesmo tempo que interprete o discurso, e que não pressuponha nenhum dos dois. (DAVIDSON, 1993, p. 14)

Para Davidson, a menos que uma linguagem seja compartilhada, ela não poderia ter meio de distinguir entre o fato de pensar se está utilizando a linguagem em questão corretamente ou incorretamente; somente a comunicação com outro pode fornecer um teste objetivo. Se somente a comunicação pode fornecer um teste objetivo do uso correto das palavras, somente a comunicação pode fornecer um critério de objetividade em outros domínios. Não temos razões suficientes para creditar a uma criatura a distinção entre o que ela considera como sendo o caso, do que é efetivamente o caso, enquanto que a criatura não tenha o critério fornecido por uma linguagem compartilhada; e sem esta distinção não há nada que se possa, claramente, chamar um pensamento (DAVIDSON, 1994a, p. 14). Uma noção do conceito de verdade, da distinção entre pensar que algo é assim e algo ser assim, depende da norma que pode ser fornecida somente por meio da comunicação interpessoal; e, é claro, a comunicação interpessoal e, certamente, a posse de qualquer atitude propositiva, depende de uma noção do conceito de verdade objetiva. Porém se o locutor e o interlocutor puderem, cada um, correlacionar as respostas do outro com a ocorrência de um estímulo partilhado, então um elemento totalmente novo é introduzido. A interação do tipo necessária requer que cada indivíduo perceba os outros como reagindo ao ambiente partilhado tanto quanto ele; somente então o ensinar pode acontecer e as expectativas apropriadas serem criadas (DAVIDSON, 1994b, p. 16).

Já que a "boa vontade" não é uma opção, mas a própria condição que nos permite ter uma teoria maleável, não tem sentido sugerir que poderíamos cair num erro massivo adotandoa. Enquanto não conseguirmos estabelecer correlação sistemática entre as frases tidas por verdadeiras, não há erro a cometer. Nos agrade ou não, a boa vontade nos é imposta, pois, se queremos compreender os outros, devemos considerar que eles têm razão sobre a maioria dos assuntos em pauta. Se podemos produzir uma teoria que reconcilia a boa vontade e as condições formais para uma teoria, fizemos tudo o que estava a nosso alcance para assegurar a comunicação. (DAVIDSON, 1993, p. 17)

\section{Considerações finais}

Procuramos em nossa análise, trazendo à tona a crítica que Wittgenstein faz à concepção agostiniana da linguagem, repensar as teorias que consideram a re- 
presentação como pilar do conhecimento. Abandonando a teoria clássica do representacionismo, é possível evitarmos problemas do cotidiano que se dão pela má interpretação do uso das palavras dentro de determinados contextos sociais. A tese de Wittgenstein se baseia na concepção que a gramática, ou as regras do emprego de nossas palavras, que se trata de "recordar", são algo ordinário, algo que é conhecido e está ao alcance de todos. Enquanto as regras de nossa gramática não são algo privado, mas de domínio público, temos desde a origem a presença da dimensão social. O falar da linguagem é parte de uma atividade ou forma de vida.

Compreender uma frase significa compreender uma linguagem. Compreender uma linguagem significa dominar uma técnica. As explicações de significado funcionam como regras em nossas práticas cotidianas com as palavras. Além disso, quando um falante sabe o que uma palavra significa ou quando a compreende, possui habilidade para explicá-la, justificar os seus usos, corrigir enganos nas aplicações desta palavra. De modo que, tal pessoa manifesta a capacidade característica do seguir regras ao usar a palavra. Dessa forma, os usos que uma pessoa faz de uma expressão, para a qual possui explicação, constituem um ato de seguir uma regra.

Em seguida, procuramos expor a contribuição teórica que Donald Davidson faz à tese de Wittgenstein, mostrando que a triangulação pode ser entendida como um pré-requisito para a formação de um Jogo de Linguagem. No momento que todas as partes estiverem interessadas em ouvir e debater suas posições em um diálogo aberto, livre dos preconceitos disciplinares, será possível chegar à raiz de muitos problemas cotidianos.

Davidson compartilha com Wittgenstein a tese de que a linguagem esta relacionada à rejeição de uma imagem representacional e da idéia de que a verdade consiste no espelhamento dos fatos. Uma sentença pode ser considerada aceitável dentro de um contexto somente se o falante e as circunstâncias da enunciação de cada sentença mencionada na definição forem contrapostos pelo falante e pelas circunstâncias da enunciação da própria definição de verdade. Também poderia ser apontado que parte da compreensão dos demonstrativos consiste em conhecer as regras pelas quais eles ajustam sua referência à circunstância.

\section{Referências bibliográficas:}

CHAUVIRÉ, Chistine. Wittgenstein. São Paulo: Top Textos, 1991.

DAVIDSON, Donald. Enquêtes sur la vérité et l'interprétation. Nîmes : Editions Jacqueline Chambon, 1993.

- Ensaios sobre a Verdade. São Paulo: Unimarco Editora, 2002.

- La mésure du mental. In: ENGEL, Pascal et al. Lire Davidson, interprétation et holisme. Paris: Editions de L'Eclat, 1994a.

- The social aspect of language. In: The Philosophy of Michael Dummet. Boston: Dordrechet, 1994b. 
FAUSTINO, Silvia. Wittgenstein e sua gramática. São Paulo: Ática, 1995.

GHIRALDELLI JR., Paulo. Richard Rorty: A filosofia do Novo Mundo em busca de mundos novos. Petrópolis: Vozes, 1999.

HACKER, P.M.S. Wittgenstein sobre a Natureza Humana. São Paulo: Editora UNESP, 2000.

HINTIKKA, Jaakko; HINTIKKA, Merrill. Uma Investigação sobre Wittgenstein. Trad. Enid Abreu Dobranszky. Campinas: Papirus, 1994.

SPANOL, Werner. Filosofia e Método no Segundo Wittgenstein: uma luta contra o enfeitiçamento do nosso entendimento: São Paulo: Loyola, 1989.

WITTGENSTEIN, Ludwig. Anotações sobre as cores. Lisboa: Edições 70, 1977.

. Da Certeza. Basil Blackwell, 1969.

. Investigações Filosóficas. São Paulo: Nova Cultural, 1999.

Investigações Filosóficas. São Paulo: Abril, 1975.

\title{
Title:
}

Rethinking language: Wittgenstein and Davidson against representacionism

\begin{abstract}
:
This study aims to explain the relevance of Wittgenstein's critique of the theory of representation to language studies. In Philosophical Investigations the author proposes the thesis of Language Games, which can be seen as a therapeutic solution not only to philosophical problems but to several areas of human knowledge. In a second moment it aims to improve the thesis of Wittgenstein taking into account the studies of Donald Davidson about the importance of the social aspect of language. To understand language's form in different contexts as Games means to understand a field where people can interact with each other through dialogues that employs the same rules for the use of words.
\end{abstract}

\section{Keywords:}

Language games; rules; representation; use 